\title{
The Effects of Boundary Spanners on Trust and Performance of Urban Governance Networks Findings from Survey Research on Urban Development Projects in The Netherlands
}

\author{
Ingmar van Meerkerk and Jurian Edelenbos
}

Article, published, full reference:

Reference:

Van Meerkerk, I., and J. Edelenbos (2014). The effects of boundary spanners on trust and performance of urban governance networks: findings from survey research on urban development projects in the Netherlands. Policy Sciences, 47 (1): 3-24.

A previous version of the manuscript was presented at:

the Annual Conference of the International Research Society for Public Management (IRSPM). Panel: Predicting the performance of public networks: Rome (2012, april 11 april 13). 


\title{
The Effects of Boundary Spanners on Trust and Performance of Urban
}

\section{Governance Networks}

\section{Findings from Survey Research on Urban Development Projects in The Netherlands}

\begin{abstract}
Previous research has extensively analyzed the role, and indicated the importance, of network management for the functioning and performance of public or governance networks. In this article, we focus on the influence of boundary spanning actors in such networks - an aspect less examined in the governance network literature. Boundary spanners are considered to be important for governance network performance. Building on the literature, we expect a mediating role of trust in this relationship. To empirically test these relationships, we conducted survey research $(\mathrm{N}=141)$ among project managers involved in urban governance networks: networks around complex urban projects that include the organizations involved in the governance process (the formulation of policies, decision making, and implementation) in these complex projects. We found a strong positive relationship between the presence of boundary spanners and trust and governance network performance. The results indicate a partially mediating role of trust in this relationship. Furthermore, we found that these boundary spanners originated mainly from private and societal organizations, and less from governmental organizations.
\end{abstract}

\section{Keywords}

Boundary spanners; trust; governance network performance; connective capacity; bridging actors; urban governance 


\section{Introduction}

Previous research has extensively analyzed the role, and indicated the importance of network management for the functioning and performance of governance networks (see for example Kickert, Klijn, and Koppenjan 1997; Meier and O'Toole 2007; Agranoff and McGuire 2001; Koppenjan and Klijn 2004; Klijn, Steijn, and Edelenbos 2010a). These studies specifically focus on the management of interaction between different actors in the network and their impact on network performance. We approach network management in another way, as we focus on a specific set of actors in that network: the boundary spanning persons that operate on the borders of their home organizations. We are interested in their role and their significance for network performance and trust building in governance networks. We focus on issue-specific networks, formed around complex urban issues in the field of spatial planning. These urban issues, like regeneration of deprived areas, are embedded in networks, in which different governmental agencies, commercial actors, non-for-profit organizations and residents reshape urban areas and are dependent of each other, as these issues cross different organizational and jurisdictional boundaries (Healey 2006; Wagenaar 2007; Klijn et al. 2010a).

Connective capacity is considered to be important to realize supported and qualitatively good outcomes in networks around complex governance issues (e.g. Koppenjan and Klijn 2004; Healey 2006; Edelenbos, Bressers, and Scholten 2013). The literature on boundary spanners pays specific attention to individuals who work at the boundaries of their organization. Competent boundary spanners are organizational members who are able to link the organization they represent with its environment (Tushman and Scanlan 1981). They are considered to be important for building trust 
within governance networks and to help improve coordination around decision making and implementation in governance networks around complex public issues (Steadman 1992; Williams 2002; Van Hulst et al. 2012). Although the effects of boundary spanning on individual organizational performance and inter-organizational collaboration and trust are (to some extent) reported in the literature (e.g. Leifer and Delbecq 1978; Tushman and Scanlan 1981; Seabright et al. 1992; Ahearne et al. 2005), there is a lack of empirical studies, especially quantitative (and mixed method) research, focusing on the functioning and presence of competent boundary spanners on the one hand and governance network performance and trust within these networks on the other. In this article, we want to empirically investigate these relationships. Building on the literature, we assume that boundary spanners have a positive influence on network performance, and that trust has a mediating role in this relationship. We conducted survey research on complex urban projects in the four largest cities in The Netherlands. These projects were developed in governance networks including public, private, and societal actors. We examined where boundary spanners in these networks were located and what the effect was of the presence of boundary spanners on the level of trust within these networks and network performance.

In the next section, we elaborate the characteristics of the issues and the type of networks on which we are focusing. In the third section, we elaborate on the concept of boundary spanners and the relationships between boundary spanners, trust, and network performance, resulting in four research hypotheses. The fourth section, dedicated to our research methods and techniques, is followed by a discussion of our findings. The final section presents conclusions and a discussion of the research results. 


\section{Governance Networks and the Need for Connective Strategies}

\section{Governance Networks: What Kind of Networks Are We Talking About?}

In contemporary public administration theory it is recognized that interdependent sets of actors provide input to many decision- making processes (e.g. Kickert, Klijn, and Koppenjan 1997; Pierre 2000; Sørensen and Torfing 2009). This has led to a developing body of research on so-called governance networks. Despite the differences in use and meaning among scholars, certain main characteristics and presumptions of governance networks can be identified:

1. They emerge and evolve around boundary-crossing public issues that cannot be solved by one actor alone but require collective actions of more actors (Sørensen and Torfing 2009). These issues cross different organizational, jurisdictional, societal, and/or functional boundaries and have a multi-value character (Kickert, Klijn, and Koppenjan 1997);

2. Therefore there is relatively high interdependency between actors to deal with these issues. The different actors around boundary-crossing public issues have to join their resources and knowledge to achieve qualitatively good outcomes (Agranoff and McGuire 2001);

3. These interdependencies require interactions between various actors with different interests, which show some durability over time (Koppenjan and Klijn 2004);

4. Steering within these interactions is complicated, because each actor is relatively autonomous in the sense that network participants typically have limited formal accountability to network-level goals (Provan and Kenis 2008), and each actor has his/her own perception about the policy problems and solutions (Teisman 2000). 
Based on these characteristics, we define governance networks as more or less stable patterns of social relations between mutually dependent actors, which form around public issues, and which are formed, maintained, and changed through interactions between the involved actors (Koppenjan and Klijn 2004). We focus on governance networks around complex urban projects that include the organizations involved in the governance process (the formulation of policies, decision making, and implementation) in these complex projects. We tested whether these networks had the characteristics of governance networks described above (see section Methods). Hence, we use a rather broad conceptualization of governance networks (cf. Klijn 2008), for example in contrast to literature focusing on policy implementation networks around public services, which have - usually - a more clear goal and are often characterized by high-density groups of actors (e.g. Provan and Kenis, 2008; Meier and O'Toole 2007). The interrelationships between the different organizations in the networks that we examined are more loosely coupled. They are issuespecific networks, since they emerge around concrete complex urban problems, dealing with specific urban development, like regeneration of certain city districts where for example city representatives, private project developers and residents form a temporary actor network in developing and implementing the project. In these networks there is a strong diversity of involved organizations, interests, and perceptions within these kinds of networks. The realization of good network performance in such an environment calls for connective capacity (Edelenbos et al. 2013).

\section{The Need for Connective Network Strategies}

The concept of connective capacity of governance networks is a response to the struggle against fragmentation in contemporary specialized governance systems in Western democracies dealing with complex societal issues (Edelenbos and Teisman 2011; Edelenbos et al. 2013). Fragmentation is defined as a whole field of separate and specialized 
organizations, and is the consequence of specialization, the main driving force for wealth and development. Further, as long as specialization is a driving force for wealth, fragmentation will be the normal societal organizational principle (Sørensen and Torfing 2009; Edelenbos and Teisman 2011).

As noted above, complex urban issues are cross-boundary in nature. Literature on urban governance stress the problems of fragmentation and complexity encountered by different kinds of stakeholders (including governmental agencies) to effectively deal with these cross-boundary issues (Wagenaar, 2007; Christensen and Lægreid 2007). As governance processes dealing with these issues evolve at the boundaries of different public, private, and societal organization, the connective activities of a variety of individuals are likely to matter for the performance of the network. While this is recognized in the literature, much of the attention goes to the role of (representatives of) central actors (e.g. lead organizations, network managers, politicians) (e.g. Meier and O’Toole 2007; Sørensen and Torfing 2009; Klijn et al. 2010; Cristofoli et al. 2012). Empirical research with a broader focus, i.e. formal and informal boundary spanners originating not only from official responsible organizations, but also from societal organizations, NGOs and community organizations, is scarce (cf. Van Hulst et al, 2012). Therefore, and in addition to many literature on network management, we focus on a broader set of boundary spanners with various organizational backgrounds, to empirically examine their influence on network performance.

\section{Boundary Spanners as Connective Agents}

The concept of boundary spanners is developed in organizational literature. Just like actors dealing with complex governance issues, organizations are also confronted with forces of fragmentation due to specialization (Tushman and Scanlan 1981). Organizations have 
different types of boundaries (e.g. horizontal, vertical, and external), which “...separate specialized subunits from each other and from external areas" (Ibid, p. 290). Successful boundary spanners are strongly linked internally and externally, so that they can both gather and transfer information from outside their sub-units. The combination of internal linkages (in their own unit or organization) and external linkages (with other units or other organizations) makes up their perceived competence and determines their boundary status (Tushman and Scanlan 1981; Levina and Vaast 2005). We want to stress that we focus on 'boundary spanners-in-practice', as Levina and Vaas (2005) call them. There is a lot of ambiguity in the literature on boundary spanning due to differences in operationalization. Confusing (formal) representational communication roles and informational communication roles (Tushman and Scanlan 1981) and/or officially nominated boundary spanners (agents who are expected to engage in boundary spanning, such as top managers) and boundary spanners-in-practice (Levina and Vaas 2005) is probably an important explanation for this ambiguity. Informational roles are involved in a two-step information flow (acquiring external information and transmitting/translating this internally and vice versa), whereas representational roles are rather involved in a one-step information flow and perform a more routine transacting or representational role. In this study we mean by boundary spanners, individuals who are involved in this two-step information flow: individuals practicing high boundary spanning activities.

In short, boundary spanners manage the interface between organizations and their environment. Boundary spanning is essentially characterized by negotiating the interactions between organization and environment in order to realize a better fit, which often also means that practices of involved organizations/systems are transformed (Steadman 1992; Levina and Vaast 2005; Edelenbos and Van Meerkerk 2011; Van Hulst et al. 2012). To effectively accomplish a better fit, boundary spanners are engaged in three main (and interrelated) 
activities: connecting or linking different people and processes at both sides of the boundary, selecting relevant information on both sides of the boundary, and translating this information to the other side of the boundary (Leifer and Delbecq 1978; Tushman and Scanlan 1981; Jemison 1984). Realizing connections between actors in governance networks is about building and maintaining sustainable relationships (Williams 2002). A common denominator in the early organizational boundary spanning literature is the emphasis on information exchange (see Jemison 1984). For selecting relevant information on one side of the boundary and translating this information to the other side of the boundary, boundary spanners need to have a feeling for the social construction of other actors (Williams 2002). According to Tushman and Scanlan (1981, 291-2), boundaries "can be spanned effectively only by individuals who understand the coding schemes and are attuned to the contextual information on both sides of the boundary, enabling them to search out relevant information on one side and disseminate it on the other." In this respect, Williams (2002) distinguishes a variety of personal characteristics of competent boundary spanners in governance networks, like empathy, being a good listener and translator to other communities. Boundary spanners understand other actors' needs (Ferguson et al. 2005) and are socalled active listeners (Williams 2002; Van Hulst et al. 2012): open to be influenced by the views of other people. This enables them to search for shared meanings (Levina and Vaast 2005). In this way, sustainable relationships with actors from different organizational backgrounds are developed and maintained. These and other personality traits are also widely stressed and discussed in (social) psychology literature and related to building effective cooperation and project performance (e.g. Thal and Bedingfield 2010; Davis 2011).

However, at this point we have to be clear that we don't study personal traits of boundary spanners from a (social) psychological point of view. Instead we depart from a 
behavioristic viewpoint and specifically look at how boundary spanners act in a governance network and which actions they perform in (trying to) connecting different stakeholders in the network. In the section "operationalization and measurement" we come back to this, by operationalizing boundary spanning as a set of actions that boundary spanners perform in the practice of urban governance.

Many studies show that the presence of competent boundary spanners leads to a better fit between organization and environment, although the results are not that straightforward. A better fit is often deduced from better organizational performance or higher levels of trust within inter-organizational cooperation. For example, positive organizational outcomes of boundary spanning individuals are found in terms of innovation (Tushman 1977), financial performance (Dollinger 1984), strategic decision-making (e.g. Jemison 1984), access to knowledge (e.g. Cross and Cummings 2004), and organizational identification of customers (e.g. Ahearne et al. 2005). Furthermore, boundary spanners could increase trust between individuals of different organizations involved in inter-organizational cooperation, but this in turn could have negative consequences in terms of organizational adaptability due to over embeddedness (Seabright et al. 1992; Brass et al. 2004). While negative outcomes of boundary spanning activities are less found in the literature, they are also less examined according to Ramarajan et al. (2011). In their study on negative consequences of boundary spanning contact in uncertain multi-organizational contexts, they found that frequent contact of boundary spanners with other organization's personnel was related to more interorganizational problems, and also related to more negative attitudes toward their own job and organization. Hence, the results are somewhat mixed, at least due to differences in operationalization, level of analysis, and organizational context (Tushman and Scanlan 1981; Perrone et al. 2003; Brass et al. 2004; Ramarajan et al. 2011). 


\section{Boundary Spanners and Governance Network Performance}

Dealing effectively with complex urban governance issues requires a high flow of information between involved actors (Wagenaar 2007). Especially, because in such a context goals are not straightforward and often diverse (Teisman 2000; Koppenjan and Klijn 2004). Furthermore, it requires mutual alignment of a diversity of stakeholders. This means that realizing vital connections between actors could increase the performance of these mutually dependent actors, as it stressed in the literature on urban regeneration and neighborhood governance (e.g. Purdue 2001; Musso et al. 2006; Van Meerkerk, Boonstra, and Edelenbos forthcoming). Also the literature on bridging ties, individuals who span and connect different structural holes in networks, stress the increase of social capital available for the network to use, if brokerage activities are performed (Granovetter 1985; Burt 2004). "A theme in this work is that behavior, opinion, and information, broadly conceived, are more homogeneous within than between groups. People focus on activities inside their own group, which creates holes in the information flow between groups, or more simply, structural holes" (Burt 2004: 353). In their study of neighborhood governance reforms in Los Angeles, Musso et al. (2006) note that bridging ties increases the reachability of information between individuals and could create more and shorter paths between groups. However, they also note that it is "a combination of strong and weak ties, [which] have direct effects on information diffusion, access to resources capacity for collective action, and political mobilization" (p. 92). This is line with the literature on boundary spanning, stressing the importance of strong internal and external linkage. ${ }^{1}$

With their role in increasing the flow of information, and translating information across organizational boundaries, connecting individuals and processes across organizational boundaries, we expect that the presence of boundary spanners contributes to the 
performance of governance networks. By network performance we refer to the substantive results of the actor network, such as the innovative character of the project plan, problemsolving capacity, and cost- efficiency (see also Klijn et al. 2010a), regarding specific urban projects. The specific operationalization and measurement is discussed in the next section. We formulate the following hypothesis to test the relationship between the presence of boundary spanners in the network and governance network performance:

H1) The presence of more boundary spanners has a positive effect on governance network performance

\section{Boundary Spanners and Trust}

In the relationship between boundary spanners and network performance it is important to consider their influence on trust building. An important driver for the emergence and sustainment of collaborative efforts in networks is trust (Huxham and Vangen 2005; Edelenbos and Klijn 2007; Ansell and Gash 2008). Going through the literature and providing a definition useful for empirical research of governance networks, Edelenbos and Klijn (2007) describe trust as referring to "a more or less stable perception of actors about the intentions of other actors, that is, that they refrain from opportunistic behavior" (p. 30).

In some literature boundary spanning activities are positively related to trust building (Williams 2002; Ferguson et al. 2005; Perrone et al. 2003). Frequent and recurring interaction with actors with different organizational backgrounds gives the opportunity to get familiar with one another's values and perspectives and to show respect to these in building common ground and framework (Steadman 1992). As competent boundary spanners are relationship builders and develop a feeling for the interests and social constructions of other actors in the governance network, we assume that they positively influence the level of trust in the governance network. 
H2) The presence of more boundary spanners leads to a higher level of trust in the governance network

\section{Boundary Spanners, Trust, and Governance Network Performance}

From previous research we know that trust has a positive influence on governance network performance (Klijn, Edelenbos, and Steijn 2010b; Huxham and Vangen 2005; Provan and Kenis 2008). Building on the literature, Klijn et al. (2010b, 196-8) mention four arguments why trust is important within governance networks for achieving supported and qualitatively good outcomes:

1. Trust reduces the risk inherent in cooperative relations, because it creates greater predictability about each other's behavior.

2. Trust increases the probability that actors will invest their resources, such as money and knowledge, in cooperation.

3. Trust stimulates learning by increasing the exchange of information and knowledge. Knowledge is partly tacit and only available, for instance, in the form of human capital. This type of knowledge can be acquired only by exchange and intensive cooperation.

4. Trust has the ability to stimulate innovation. Innovations emerge by confronting different ideas and expertise. Trust can facilitate innovation by reducing uncertainty about opportunistic behavior and by making vertical integration and coordination - which could hinder innovation - less necessary.

We acknowledge that in literature the relationship can be vice versa, i.e. that good performance and continued cooperation lead to increased trust (e.g. Lewicki and Bunker, 
1996), as 'good results' like consensus on decisions and satisfaction with concrete implementation of decisions strengthen trustworthiness among stakeholders (Edelenbos and Klijn, 2007). However, for this study we explicitly focus on how trust leads to higher network performance. To test this causal relationship we formulate the following hypothesis:

H3) A higher level of trust between actors involved in the governance network leads to better network performance

Assuming that boundary spanners positively influence network performance and trust, and that trust also contributes to network performance, we expect a partially mediating role of trust:

H4) Trust partially mediates the relationship between the presence of boundary spanners within the governance network and governance network performance

In the model below, the various hypotheses are combined in the conceptual framework we will test. We have to note that we did not include context variables in our model, such as the political opportunity structure or the network position of actors. Previous research shows that such context factors are important for both the extent in which (and what kind of) connective activities are undertaken and the effectiveness of boundary spanning activities (Stevenson and Greenberg 2000). However, our main goal is to examine where boundary spanners are located and whether boundary spanners effect the level of trust within governance networks and network performance. Hence, we have left this contextual dimension out of our research.

The following section addresses data collection and the measurement of our core variables. Then, we describe the extent to which boundary spanners were present in the 
urban governance networks researched and test our model.

[Figure 1 here]

\section{Methods}

\section{Sample and Data Collection}

We collected data from a web-based survey held in 2011 (April-July) among leading project managers in the four largest cities of the Netherlands (Amsterdam, Rotterdam, The Hague, and Utrecht ${ }^{2}$ ) and managers within two private firms (P2 and DHV) that operate as project managers in these four cities. The organizations involved actively participated in the survey in two ways. Firstly, they organized the e-mailing to the project managers and encouraged them to participate in the survey. Secondly, we held three preparation sessions with eight project managers from the four participating cities to validate our survey approach and questionnaire. In these sessions, we discussed the relevance of the items and whether they understood all the survey questions. In this way, we were able to improve our questionnaire: we added some items and we changed the formulation of questions. In the next section, we present and discuss the items that we used to measure our core variables. These items are largely derived from the scientific literature, using existing scales.

Each respondent is a manager involved in specific urban projects in one of the four cities. We consider the set of actors involved in each (urban) project as a governance network: a governance network consists of actors (local government, project developers, building companies, residents, societal stakeholder groups, etc.) that have interdependent relationship with one another in developing and implementing an urban project. Each project manager 
was asked as a respondent to fill in the questionnaire with a specific urban project in mind in which they are/were most intensively involved, and which they had to keep in mind when responding to all questions. We explicitly selected the project managers because they know what is going on in the surveyed projects and are also equipped to answer specific questions concerning boundary spanning, project management, relations with principal, and so forth. To safeguard the independence of our data, we arranged with participating organizations that they send e-mails to each leading project manager of a specific urban project. In this way, we made sure we had one manager for each project. We sent one follow-up by e-mail. In addition, we called respondents to remind them about the survey. ${ }^{3}$

[Table 1 here]

Table 1 describes the population of the project managers from the four largest municipalities of the Netherlands and from two private firms. The table also shows the response rate, which is 41 percent $(\mathrm{N}=141)$.

\section{Unit of analysis}

In this research we study the relationship between (the presence of) boundary spanners in the governance network and network performance, with trust (among people in the network) as an partly mediating variable in this supposed relationship. Our unit of analysis is on the level of the governance network. We study the presence of boundary spanners in the network, which don't necessarily be the official project manager but also can turn out to be other persons (resident, private project developer, etc.). We therefore asked the leading project manager of each network to what extent they witnessed boundary spanners in the network. As will be further elaborated in the section "measurement of variables", these 
persons where referred to as performing explicit activities to connect different actors and processes in the network with their home organization. The variables performance and trust are also analyzed on the network level. Performance is measured by asking the respondent for example to score the durability and the innovative character of the project results in relation to the urban issue at stake (see section "measurement of variables"). The level of trust was measured by explicitly asking the respondent to indicate and score the level of trust among (main) actors in the governance network.

We have to note here that our data is cross-sectional and were collected at a single point in time. More research is therefore required to sustain the causal relationships.

\section{Governance Networks around Complex Urban Projects}

The urban projects could be described as complex projects developed within governance networks. The networks around the projects on which the managers reported, mostly included more than ten organizations (66\%). In the results section, when we discuss the locus of boundary spanners, more specific information is presented about the types of organizations included in the networks. Most of the networks included societal interest groups (94.3\%), private developers (78.6\%), architectural firms (79.4\%), and different governmental organizations.

We also checked whether the urban projects were really boundary-crossing public issues. We measured this by focusing on task complexity: how many and what kinds of development and/or spatial activities are included in the project (Klijn et al. 2010a)? Consequent to the preparation sessions with the eight project managers, we asked about six different kinds of spatial activities/tasks: infrastructure (rail and public highways), water management, housing, social facilities (schools, sports facilities), development and/or regeneration of business areas, and development of city parks (cf. Klijn et al. 2010a). 
Measured on a five-point Likert scale, on average more than three of these tasks $(M=3.76)$ play a medium to large part in the projects, which confirms the boundary-crossing nature of the projects.

\section{Measurement of Variables}

In this section we discuss the different scales we used to measure our core variables trust, the presence of boundary spanners, and governance network performance. Subsequently we discuss the validity and reliability of these scales. Table 2 presents the specific items of the scales, their factor loadings, and the construct reliabilities. The descriptive statistics and the correlation matrices can be found in table 4 .

Boundary Spanning Actors. We could not find an existing scale for measuring the presence of boundary spanners in governance networks. To develop a reliable scale we build on scales in the business literature (e.g. Jemison 1984; Ferguson et al., 2005) and on the literature about the activities of boundary spanners (see section Boundary Spanners as Connective Agents). We distinguish five different boundary spanning activities as an indication of the presence of boundary spanners in the governance networks:

1. Good information exchange between the network and the home organization (e.g. Tushman and Scanlan 1981);

2. Building and maintenance of sustainable relationships between organizations in the network (Williams 2002; Klijn et al. 2010a);

3. Making effective connections between developments in the network and work processes in the home organization (cf. Jemison 1984; Steadman 1992);

4. A feeling for what is important for other organizations in the network (Williams 2002; Ferguson et al., 2005);

5. Timely mobilization of their home organization when this is considered 
necessary/useful regarding developments in the network (cf. Klijn et al. 2010a; Ferguson et al., 2005).

In the survey, we asked the respondents whether they thought there were many persons active in the network who show these kinds of activities. Furthermore, we asked where these persons were located (i.e. their organizational background). The results will be discussed in the next section. Together, the items to measure the presence of boundary spanners form a scale with a Cronbach's Alpha of 0.84 , by which we could consider the scale as reliable. The mean score on the presence of boundary spanning persons is 3.37 (SD $=0.67)$ on a five-point Likert scale, indicating a moderate presence of boundary spanners in the governance networks.

Trust between Actors in the Governance Network. To measure trust within the network, we build strongly on the existing scale of Klijn et al. (2010b), consisting of different dimensions derived from the business literature, including the notions of agreement trust, benefit of the doubt, reliability, and goodwill trust. Because the project managers in the sessions to improve our questionnaire argued that for them an important additional element of trust is 'feeling a good connection with the other actors', we improved the scale by adding this aspect of trust.

Performance of Governance Networks. There has been much discussion in the governance literature on how to measure performance of governance networks. We want to stress that there is no particular best approach (e.g. Provan and Milward 2001). In urban governance networks multiple stakeholders are involved which pursue different goals. Therefore, picking a specific goal of one of the nodes to measure network performance is not considered adequate (cf. Provan and Milward 2001). Furthermore, measuring network 
performance is problematic because decision-making processes in governance networks are lengthy, and actors' goals can change over time. Goal displacement is the negative term for this phenomenon, and learning is the positive term (see Koppenjan and Klijn 2004). We follow the approach of Klijn et al. (2010a) to deal with this problem. They used perceived network performance as a proxy for measuring network performance. Furthermore, they used more than one criterion to measure this. We used their scale, which takes into account that goals change and that actors have different views about the outcomes.

[Table 2 here]

\section{Measurement Analyses}

Analysis of reliability, convergent validity, and discriminant validity. We conducted confirmatory factor analyses to assess convergent and discriminant validity. The overall fit of the measurement model was tested by the fit indices CFI and RMSEA. The CFI index has a value of 0.973 and the parameter RMSEA has a value of 0.040 (PCLOSE larger than 0.050 , i.e. 0.731 , which indicate a good fit of the measurement model with the data (Byrne 2010).

All factor loadings are larger than 0.50, a very conservative cut-off level (Hair et al., 1995), which is a first important indicator demonstrating convergent validity. Furthermore, the composite reliability indexes of the three scales all exceed the .60 threshold (Fornell and Larcker 1981).

To further assesses the reliability of the measures we computed corrected item-tototal correlations and Cronbach's alphas. All items had corrected item-to-total correlations that were greater than .40, which represents a general threshold (Field, 2005). All 
Cronbach's alphas exceeded the widely accepted cutoff value of .70.

To establish discriminant validity, we compared the average variance extracted (AVE) with the squared inter-construct correlation estimates (SIC). The AVE of all three constructs are larger than the corresponding squared inter-construct correlations, which means that the indicators have more in common with the construct they are associated with than they do with other constructs.

Testing for General Method Bias. An important issue with respect to measurement is that our data are all self-reported and based on a single application of a questionnaire. This can result in inflated relationships between variables due to common method variance, that is, variance that is due to the measurement method rather than the constructs themselves (Podsakoff and Organ 1986). We therefore conducted a Harman one-factor test to evaluate the extent to which common method variance was a concern. A factor analysis was conducted on all 15 items used to measure the perceptual variables covered by the hypotheses (background variables such as phase of the project were left out). No single factor accounted for the majority of the explained variance (i.e. 36.2\%). Although the above analysis does not totally rule out the possibility of same-source, self-report biases, it does suggest that general method variance is probably not an adequate explanation for the findings obtained in this study (Podsakoff and Organ 1986).

\section{Control Variables}

We selected four control variables to test whether the measured effects on our dependent variables, trust and network performance, are not caused by certain specific characteristics of the project or the reporting managers. With regard to the projects, we included two control variables in our analyses, based on the literature. The literature suggests that increased task complexity increases the difficulty of realizing effective and efficient network 
performance (see Klijn et al. 2010a). Therefore, we included task complexity as a control variable (more information on this variable is reported at the beginning of this section). Secondly, we examined the phase of the project. This variable is about the realized activities within the project, such as the development of the final project plan and the realization of the first physical constructions. With regard to urban projects, performance in terms of effective and durable solutions for spatial issues become more visible if projects are in a later project phase. The level of trust could also be influenced by the phase of the project, for example because the diversity and intensity of interactions between organizations change in the development of urban projects (Edelenbos and Klijn 2007). In 81 percent of the sample projects, a master plan has been developed and has been established by the city council, and in 40 percent the first physical constructions have been built. With regard to the reporting managers, we included the number of years the respondent has been involved in the project as the manager. This is a general check on whether the respondent has participated for a sufficiently substantive amount of time to actually be able to make experience-based judgments. The mean score on this variable is 3.0 years, which is a considerable amount of time. However, the standard deviation (2.1 years) is quite high, and this strengthens the case to include this variable as a control. Furthermore, we included the general experience (measured in years) of the project manager with complex urban projects as a control variable. Our main argument here is that, through increased time spent working in the field, network managers will get more experience in terms of analyzing and understanding network relationships, and more skills in bringing people together to promote sense-making among actors in the governance network as well as to realize collaborative relationships (Juenke 2005). Although most project managers involved in this survey are relatively experienced in the management of urban projects (more than 13 years on average and a modus of seven years), there are strong differences (standard 
deviation of 7.2 years).

\section{Results}

[Table 3 around here]

\section{Description of Locus of Boundary Spanners}

Table 3 and figure 2 present the descriptive statistics of the locus and the extent to which boundary spanners were present in the different organizations in the governance networks on which our respondents reported. Firstly, it is interesting to note that societal interest groups (94.3\%), private developers $(78.6 \%)$ and architectural firms $(79.4 \%)$ are very often part of the governance networks around complex urban issues (see table 4). In most of the cases, different governmental layers are also part of the governance network: national government $(61.3 \%)$, the province $(59.9 \%)$, and sub local government $(58.6 \%)$. This confirms that networks around complex urban governance projects often have a multi-level character (cf. Kern and Bulkeley, 2009).

[Figure 2 here]

We asked the managers to indicate the extent to which boundary spanners were present in the different organizations in the governance network. ${ }^{4}$ Interestingly, there is a strong difference between the perceived presence of boundary spanners in governmental organizations compared to private and societal organizations in the governance network. Boundary spanners originate mainly from private companies and societal organizations. According to the managers, boundary spanners are less present in the governmental organizations with which they have contact (i.e. national government, regional government, 
and other local governments). An explanation could be that governmental representatives in the governance network are less flexible because they work in a more hierarchical and bureaucratic organizational context than representatives of societal and private actors (e.g. Edelenbos and Van Meerkerk 2011). Furthermore, the fragmentation of the governmental institutional set-up could provide an explanation. Dutch governmental organizations are highly sector or domain oriented. According to several authors (e.g. Klijn and Teisman 2003; McGuire and Agranoff 2011), such strict domain or turf demarcations act as barriers to cooperation in governance networks. However, further research is needed to examine this difference in the perceived presence of boundary spanners.

[Table 4 here]

\section{Correlations}

Table 4 shows the correlations among all the variables included in the analysis. The table shows that the perceived presence of boundary persons in the governance network is strongly positively correlated with trust $(r=0.55)$ and network performance $(r=0.44)$; this is in line with our formulated hypotheses. Furthermore, trust is also positively correlated with network performance $(r=0.40)$; this is line with previous research (see Klijn et al. 2010b). There are also some correlations between the control variables and the core variables. The highest correlation in this respect exists between trust and the phase of the project $(r=0.22)$. Projects that are in a later stage show a higher level of trust in the governance network. This is not that surprising. As is also described above, projects that are in a later phase have an increased chance of repeated interaction between organizations, which is an important factor for building trust (Edelenbos and Klijn 2007).

The correlations described above give us a first indication of the impact of boundary spanners on trust within the governance network and network performance. They support 
our conceptual model. In the next section we will use structural equation modeling to test all the relationships in our conceptual model.

\section{Impact of Boundary Spanners on Trust and Governance Network Performance}

In figure 3 the results of the structural equation modeling analysis are displayed. ${ }^{5}$ The standardized estimates and the subsequent impact on trust and governance network performance are shown. The first three hypotheses are confirmed in this structural model. The standardized direct effect of boundary spanners on network performance is 0.34 ( $\mathrm{p}<$ 0.05). Moreover, the effect of boundary spanners on the level of trust in the governance network is strong. We found a standardized regression coefficient of $.65(\mathrm{p}<0.01)$, which corresponds with an explained variance of $42 \%$ of the level of trust. The standardized direct effect of boundary spanners on governance network performance is $0.34(\mathrm{p}<0.05)$. With regard to the relationship between trust and network performance, we found a standardized regression weight of $.28(\mathrm{p}<0.05)$. This is line with previous research, although the effect of trust on network performance is less strong than we found in previous research (B, A, and C 2010). This can be explained by the fact that boundary spanning turns out to be a very strong factor next to trust and accounts for a large part the positive relation with network performance in this model.

These results provide a first indication of a partially mediating role of trust in the relationship between boundary spanners and network performance. The standardized indirect effect of boundary spanners on governance network performance is $0.18(0.65 *$ $0.28)$, which results in a standardized total effect of $0.52(0.18+0.34)$. To estimate the significance of this mediation effect, we performed the bias-corrected bootstrap method described by Shrout and Bolger (2002). We requested 2000 bootstrap samples. The indirect effect of boundary spanners on network performance is just above the significance level of 
$0.05(\mathrm{p}=0.053)$. Therefore, we cannot confirm hypothesis four, but the results do indicate a partially mediating role of trust. The relatively small effect of trust on governance network performance compared with previous research could be of importance here.

[Figure 3 here]

Model Fit. We used several statistics to evaluate the model's goodness of fit. Firstly, the $\chi^{2} /$ degrees of freedom ratio is 1.22 and the CFI is 0.97 . Secondly, the indices for the badness of fit were conducted by the RMSEA, which is less than 0.05 (i.e. 0.04), and the PCLOSE, which is larger than 0.05 (i.e. 0.73). These indices indicate that the model has a good fit (Anderson and Gerbing 1988; Byrne 2010).

Control variables. The final step in the analysis was the examination of the control variables. Control variables considered and dropped from the final model due to nonsignificant results were the controls on the respondent (Years of involvement, Years of experience). The controls on the project (task complexity and project phase) did not show a significant relationship with the dependent variables (trust and network performance) either, but showed positive (small) relationships with the presence of boundary spanners. Task complexity requires more boundary spanning activities $(\beta=.18, p<0.05)$ as do projects which are in a later phase $(\beta=.22, p<0.05)$.

\section{Conclusions and Discussion}

In this article, we have focused on the role of boundary spanners in complex urban networks in the four largest cities in the Netherlands. There is an emerging body of literature on the importance of individuals in inter-organizational settings (e.g. Williams 
2002). In the collaborative governance and network management literature, distinctive skills and strategies of network managers are defined and examined in this respect. This research complements this literature in two ways. Firstly, it directs attention to the role of different connective agents in governance networks rather than focusing on the network manager alone. Secondly, empirical studies, especially large $\mathrm{N}$ research, on the effects of boundary spanners on network performance and trust building are scarce.

Our research has some limitations. Firstly, this study has focused on specific kinds of governance networks; all the networks studied were in the field of urban development and restructuring. These results cannot automatically be assumed to hold also for other types of public projects or policy domains, such as (social) service delivery networks (Meier \& O'Toole 2007). Secondly, the study was conducted in The Netherlands, and the projects are all Dutch. The results may differ in other countries with different decision-making cultures (e.g. Skelcher et al. 2011). In The Netherlands there exists a consensual political and administrative culture, in which deliberation and consultation among stakeholders is relatively common practice. Connective capabilities may therefore have a more direct effect on the level of trust and performance (cf. Torfing \& Triantafillou 2011, p. 267). Furthermore, we based our analysis on the perceptions of the leading public manager within the networks. Although such an approach is certainly not unusual (e.g. Moynihan and Pandey 2005; Klijn et al. 2010a) and enabled us to include a large number of networks in our analysis, we have to be careful in making generalizations. For example, the personality of the manager could be a factor influencing the manager's perception of boundary spanning activities of other actors in the network. Managers may differ in the way they value/perceive interdependencies between actors, the variety of boundary spanning activities, and their own role in this matter. However, we believe that, within the constraints of this research, we can draw meaningful conclusions.

A first conclusion is that boundary spanners are important people in complex (urban) 
governance networks. Because of the complex, multi-actor, and compounded character of these networks, the role of people who intentionally aim at crossing organizational borders and connecting people and organizations is highly important. This research stresses the importance of the connective capabilities of different individuals interacting in governance networks. We have shown in our research that their connecting activities are important in realizing network performance and trust building. This is often assumed in the literature (c.f. Williams 2002) but only seldom substantiated by empirical research. The results show that people operating on the borders of organizational structures in the governance network are important for connecting different actors and their viewpoints and interests. In this way, trustworthy relationships can be developed and network performance can be improved.

A second conclusion is that, in our research, boundary spanners originated mainly from private and societal organizations, and less from governmental organizations (at all levels: national, regional, and - especially - local). It seems more difficult for governmental agents to operate at the borders of their home organization. The internal fragmentation of their bureaucratic organization or agency turf may both be explanatory factors, hampering their connective capacity towards other organizations in the governance network (c.f. McGuire and Agranoff 2011). This provides us with the insight that representatives from private and societal organizations are important in spanning the boundaries among private, societal, and public organizations in the governance network, and bringing these organizations more closely together in realizing network performance. It shows that (officially appointed) network managers are also dependent on the way other individuals in the network manage the interfaces with other organizations. In this respect, the network management research could be extended to further examine this relationship between network management and the connective behavior of other actors, and its effect on network performance. 
However, more research - especially comparative qualitative research - should be undertaken to explain this difference in boundary spanning capacity of private versus public actors. This stresses the need to consider the organizational context in which boundary spanners operate, which is in line with organizational literature on boundary spanning which shows that, for example, a higher level of autonomy of the boundary spanner is related to a higher level of trust of external agents in the boundary spanner (Perrone et al. 2003). In addition, macro-structural context variables, such as the political opportunity structure and network position of actors, should also be included in further research, as such context factors influence the effectiveness of boundary spanning activities and the willingness of agents to perform such activities (Stevenson and Greenberg 2000).

The value and relevance of the results of this study for the practice of policy making is in our view that organizations need to acknowledge the importance and value of boundary spanning persons and activities in improving organizational and network performance. In contemporary complex society, the role of specific connecting individuals increases in importance (cf. Edelenbos et al. 2013; Van Hulst et al. 2012; Van Meerkerk et al. forthcoming). Many policy making processes evolve in a network context, which stress the importance of people who develop connections among different parts in the network in finding common ground, mutual understanding and coordinated action. While many governments have a tendency to invest in new structures (reorganization) or organizational form to deal with complex governance issues (cf. Kort and Klijn, 2011), our study provides the insight that this one-dimensional approach is not enough, and need at least to be accompanied by investment in the connective and relational capabilities of people dealing with complex, cross-sectoral and multi-actor policy issues. 


\section{Notes}

1. Although the literature on boundary spanning and the more sociological research on bridging ties and structural holes show strong similarities, there is relatively little mutual awareness or interaction (Fleming and Waguespack 2007). While an extensive comparison is beyond the scope of this article, we could note that the sociological research is relatively more focused on the consequences of the network structure, for example, for the position of the broker (putting the broker in a position of power) (see Fuchs 2010), where the boundary spanning literature is more focused on the nature of agency, i.e. the effects of boundary spanning activities for (inter)organizational performance. We follow this later perspective, examining the effects of boundary spanners on network performance.

2. These four cities are relatively the largest cities in The Netherlands. Amsterdam has 783,000 inhabitants, Rotterdam 611,000, The Hague 497,000 and Utrecht 313,000. The fifth city, Eindhoven has 214,000 inhabitants, which is substantially lower.

3. The municipalities of The Hague and Rotterdam did not provide us with the telephone numbers of the project managers. In Rotterdam, we visited the managers' departments to promote the survey.

4. The different types of organizations were derived from the literature (e.g. Koppenjan and Klijn 2004; Klijn et al. 2010a) and the sessions with the eight project managers to validate our survey questionnaire (see section Methods).

5. We used AMOS Version 18.0. 


\section{References}

Agranoff, R. and M. McGuire. 2001. Big Questions in Public Network Management Research. Journal of Public Administration Research and Theory 11 (3): 295 - 326.

Ahearne, Michael, C.B. Bhattacharya, and Thomas Gruen (2005), "Antecedents and Consequences of Customer-Company Identification: Expanding the Role of Relationship Marketing," Journal of Applied Psychology, 90 (3), 574-85.

Anderson, James C., and David W. Gerbing. 1988. Structural Equation Modeling in Practice: A Review and Recommended Two-Step Approach. Pshychological Bulletin 103 (3): 411423.

Ansell, C. and Gash, A. 2008. Collaborative governance in theory and practice. Journal of Public Administration Research and Theory 18(4): 543-571.

Brass, Daniel J., Joseph Galaskiewicz, Henrich R. Greve, and Wenpin Tsai. 2004. Taking stock of networks and organizations: A multilevel perspective. Academy of Management Journal 47(6): 795-817.

Burt, Ronald S. (2004). Structural Holes and Good Ideas. American Journal of Sociology. 110 (2): $349-399$

Byrne, Barbara M. 2010. Structural Equation Modeling with AMOS. Basic Concepts, Applications, and Programming. New York: Routledge. 
Christensen, T., and P. Laegreid. 2007. The whole-of-government approach to public sector reform. Public Administration Review, 67(6): 1059-1066.

Costello, Anna B., and Jason W. Osborne. 2005. Best Practices in Exploratory Factor Analysis: Four Recommendations for Getting the Most From Your Analysis. Practical Assessment, Research \& Evaluation, 10(7).

Cristofoli, Daniela, Josip Markovic, Marco Meneguzzo 2012 Governance, management and performance in public networks: How to be successful in shared-governance networks. Journal of Management and Governance. DOI 10.1007/s10997-012-9237-2

Cross, R., \& Cummings, J. N. 2004. Ties and network correlates of individual performance in knowledgeintensive work. Academy of Management Journal, 47(6): 928-937.

Davis, Steven A. (2011). Investigating the Impact of Project Managers' Emotional Intelligence on Their Interpersonal Competence. Project Management Journal, 42(4): 37-57

Dollinger, M. J. 1984 'Environmental boundary spanning and information processing effects on organizational performance', Academy of Management Journal, 27(2): 351-368.

Edelenbos, J. \& Klijn, E.H. (2007). Trust in complex decision-making networks; a theoretical and empirical exploration. Administration and Society, 39(1), 25-50. 
Edelenbos, J., and G.R. Teisman (2011). Symposium on water governance. Prologue: water governance as a governments actions between the reality of fragmentation and the need for integration. International Review of Administrative Sciences, 77(1), 5-30.

Edelenbos, J. and I. van Meerkerk (2011). Institutional Evolution within Democracy: Local Self-Governance Meets Local Government, in: Torfing, J. and P. Triantafillou (eds, 2011), Interactive Policy Making, Metagovernnace and Democracy, Colchester: ECPR Press: 169186.

Edelenbos, J., N. Bressers, and P. Scholten (2013). Water Governance as Connective Capacity. London: Ashgate

Ferguson, Ronald J., Michèle Paulin, and Jasmin Bergeron. 2005. Contractual governance, relational governance, and the performance of interfirm service exchanges: the influence of boundary-spanner closeness. Journal of the Academy of Marketing Science, 33(2): 217-234.

Field, Andy P. (2005). Discovering Statistics Using SPSS (Second Edition). London: Sage.

Fleming, L., and D. Waguespack 2007 "Boundary spanning, broker age, and the emergence of leadership in open innovation communities." Organization Science, 18 (2): 165-180. 
Fornell, Claes, and David F. Larcker. 1981. Evaluating structural equation models with unobservable variables and measurement error. Journal of Marketing Research, 18: 3950.

Fuchs, E. R. H. 2010. Rethinking the role of the state in technology development: DARPA and the case for embedded network governance. Research Policy 39(9) 1133-1147.

Granovetter, M. S. (1985). Economic action and social structure: The problem of embeddedness. American Journal of Sociology, 91(3): 481-510.

Hair, Joseph F., Rolph E. Anderson, Ronald L. Tatham, and William C. Black. 1995. Multivariate Data Analysis. Prentice-Hall: Upper Saddle River, NJ.

Huxham, C., and S. Vangen. 2005. Managing to collaborate; the theory and practice of collaborative advantage. London: Routledge.

Levina, N., and Vaast, E. 2005 "The Emergence of Boundary Spanning Competence in Practice: Implications for Implementation and Use of Information Systems," MIS Quarterly (29:2), Jun 2005, pp 335-363.

Jemison, David B. 1984. The Importance of Boundary-Spanning Roles in Strategic Decision Making. Journal of Management Studies, 21(2): 131-152.

Juenke, E. G. 2005. Management Tenure and Network Time: How Experience Affects Bureaucratic dynamics. Journal of Public Administration Research and Theory 15(1): 
$113-131$.

Kern, K. and H. Bulkeley. 2009. Cities, Europeanization and Multi-Level Governance: Governing Climate Change through Transnational Municipal Networks. Journal of Common Market Studies, 47(2): 309-332.

Kickert, W. J. M., E.H. Klijn, and J.F.M. Koppenjan, ed. 1997. Managing complex networks: Strategies for the public sector. London: Sage.

Klijn, Erik-Hans, and Geert Teisman. 2003. Institutional and strategic barriers to publicprivate partnerships: An analysis of Dutch cases. Public Money and Management, 23(3): $137-46$.

Klijn, E.H. 2008. Governance and Governance Networks in Europe: An Assessment of Ten Years of Research on the Theme. Public Management Review 10(4): 505-525.

Klijn, E.H., Edelenbos, J. \& Steijn, A.J. (2010b). Trust in governance networks; its impact and outcomes. Administration and Society, 42(2), 193-221.

Klijn, E.H., Steijn, A.J. \& Edelenbos, J. (2010a). The impact of network management strategies on the outcomes in governance networks. Public Administration, 88(4), 1063-1082.

Koppenjan, J., and E.H. Klijn. 2004. Managing uncertainties in networks. London: Routledge. 
Leifer, Richard, and Andre Delbecq. 1978. Organizational/Environmental Interchange: A Model of Boundary Spanning Activity. The Academy of Management Review, 3(1): 40-50.

Lewicki, R.J. and B.B. Bunker (1996), Developing and maintaining trust in work relationships, in: Kramer, R.M. en T.R. Tyler (eds.), Trust in Organizations, London: Sage: 114-139.

McGuire, M. and R. Agranoff. 2011. The Limitation of Public Management Networks. Public Administration, 89(2): 265-84.

Meier, K., and L.J. O’Toole. 2007. „Modelling Public Management: empirical analysis of the management-performance nexus." Public Administration Review 9(4): 503-527.

Moynihan Donald P. and Sanjay K. Pandey. 2005. Testing how management matters in an era of government by performance management. Journal of Public Administration Research and Theory 15 (3): 421-439.

Musso, J. A., Weare, C., Oztas, N., \& Loges, W. E. (2006). Neighborhood governance reform and networks of community power in Los Angeles. The American Review of Public Administration, 36, 79-97.

Pierre, J. ed. 2000. Debating governance: Authority, democracy, and steering. Oxford: Oxford University Press.

Podsakoff, P. M., and D.W, Organ. 1986. „Self-reports in organizational research: 
Problems and prospects. Journal of Management, 12: 531-544.

Provan, K.G., P. Kenis (2008). Modes of network governance: structure, management, and effectiveness. Journal of Public Administration Research and Theory, 18 (2) 229252.

Provan, K.G., and B.H. Milward. 2001. Do Networks Really Work? A Framework for evaluating Public-Sector Organizational Networks. Public Administration Review, 61(4): 414-423.

Purdue, D., 2001. Neighbourhood governance: leadership, trust and social capital. Urban studies, 38, (12), 2211-2224.

Ramalingam, S. and Mahalingam, A. (2011) Enabling conditions for the emergence and effective performance of technical and cultural boundary spanners in global virtual teams. Engineering Project Organization Journal, 1(2), 121-41

Seabright, M. A., Levinthal, D. A., \& Fichman, M. 1992. Role of individual attachments in the dissolution of interorganizational relationships. Academy of Management Journal, 35(1): $122-160$.

Shrout, P. E., \& Bolger, N. (2002). Mediation in experimental and nonexperimental studies: New procedures and recommendations. Psychological Methods, 7, 422-445. 
Skelcher, C., E.H. Klijn, D. Kübler, E. Sørensen, and H. Sullivan. 2011. Explaining the Democratic Anchorage of Governance Networks: Evidence from Four European Countries. Administrative Theory and Praxis, 33(1): 7-38.

Sørensen E, Torfing J (2009) Making Governance Networks Effective and Democratic Through Metagovernance. Public Administration 87(2), 234-258.

Steadman, H.J. 1992. Boundary Spanners: A Key Component for the Effective Interactions of the Justice and Mental Health Systems. Law and Human Behavior, 16(1): $75-87$.

Stevenson, William B., and Danna Greenberg 2000 Agency and Social Networks: Strategies of action is a social structure of position, opposition, and opportunity. Administrative Science Quarterly 45(4):651-678.

Teisman, G.R. (2000) Models for Research into Decision-Making Processes: On Phases, Streams and Decision-Making Rounds, Public Administration, 78(4), pp. 937-56.

Thal, Alfred E. Jr., and Bedingfield, John D. 2010. Successful project managers: an exploratory study into the impact of personality. Technology Analysis and Strategic Management, 22(2): 243-259

Tushman, Michael L., and Thomas J. Scanlan. 1981. Boundary Spanning Individuals: Their 
Role in Information Transfer and Their Antecedents. The Academy of Management Journal, 24(2): 289-305.

Van Hulst, M., De Graaf, L., and Van den Brink, G. 2012. The work of exemplary practitioners in neighborhood governance. Critical Policy Studies 6(4): 434-451.

Van Meerkerk, I.F., Boonstra, B. \& Edelenbos, J. (forthcoming). Self-Organization in Urban Regeneration: A Two-Case Comparative Research. European Planning Studies. DOI: $10.1080 / 09654313.2012 .722963$

Williams, Paul. 2002. The competent boundary spanner. Public Administration, 80: 103 124. 
Figure 1 Conceptual Model

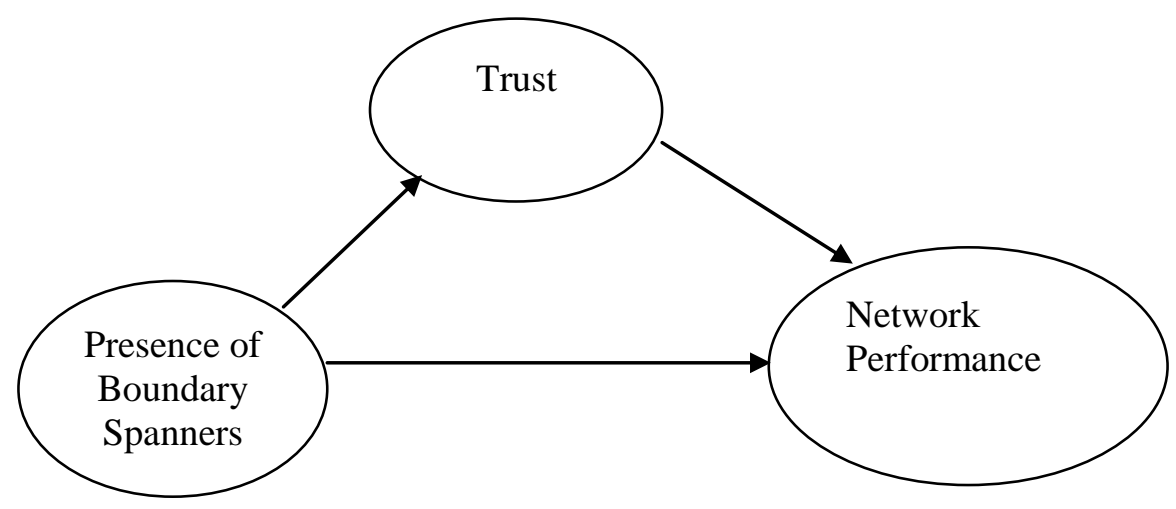


Table 1 Population and Response of the Survey

\begin{tabular}{lccl}
\hline & Population & Response (absolute) & Response (percentage) \\
\hline Municipalities (4) & 288 & 117 & $40.6 \%$ \\
Private organizations (2) & 57 & 24 & $42.1 \%$ \\
Total & 345 & 141 & $40.9 \%$ \\
\hline
\end{tabular}


Table 2 Measurement Items and Constructs' Reliability

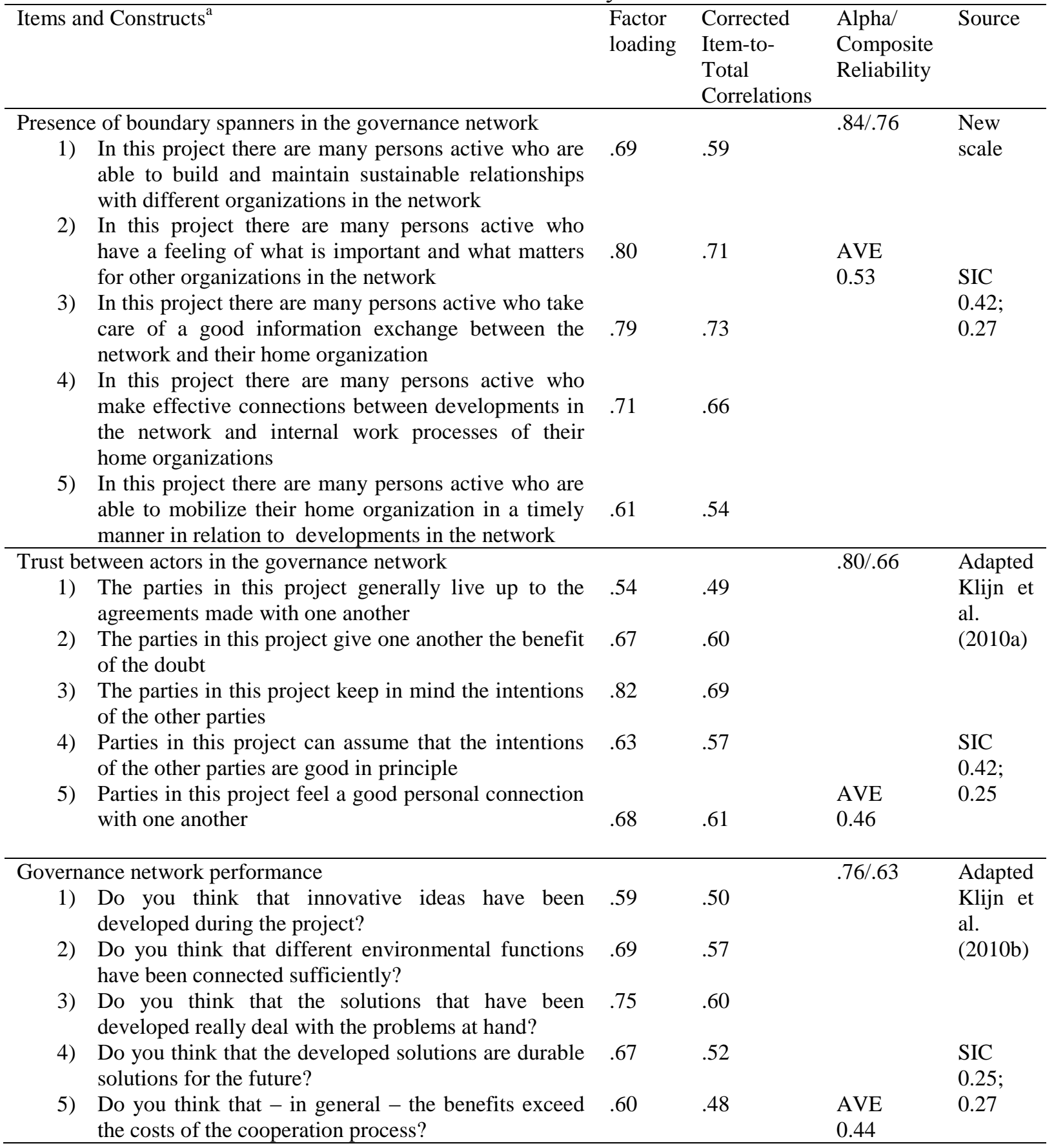

a. All the items were measured on a five-point Likert scale ranging from (1) Strongly disagree to (5) Strongly agree. 
Table 3 Descriptive Statistics of the Presence of Boundary Spanners in Different Organizations in the Governance Network $(\mathrm{N}=141)$

\begin{tabular}{lccc}
\hline Organization / interest group & Mean* & $\begin{array}{c}\text { Standard } \\
\text { deviation }\end{array}$ & $\begin{array}{c}\text { Proportion of the governance networks } \\
\text { (percentage) }\end{array}$ \\
\hline National government & 2.75 & 1.09 & 61.3 \\
Province (regional government) & 2.67 & 0.96 & 59.9 \\
Other local government(s) & 2.75 & 1.02 & 47.5 \\
Sub local government & 3.66 & 1.12 & 58.6 \\
Housing association(s) & 3.48 & 0.95 & 60.7 \\
Private developer(s) & 3.75 & 1.02 & 78.6 \\
Architectural firm(s) & 3.45 & 0.89 & 79.4 \\
Societal interest groups (e.g. & 3.46 & 0.93 & 94.3 \\
environmental, inhabitants) & & & \\
Economic interest groups & 3.10 & 0.94 & 63.8 \\
\hline
\end{tabular}

\footnotetext{
*Measured on a five-point Likert scale ranging from (1) Strongly absent to (5) Strongly present.
} 
Figure 2 The Presence of Boundary Spanners in Different Organizations in the

\section{Governance Network}

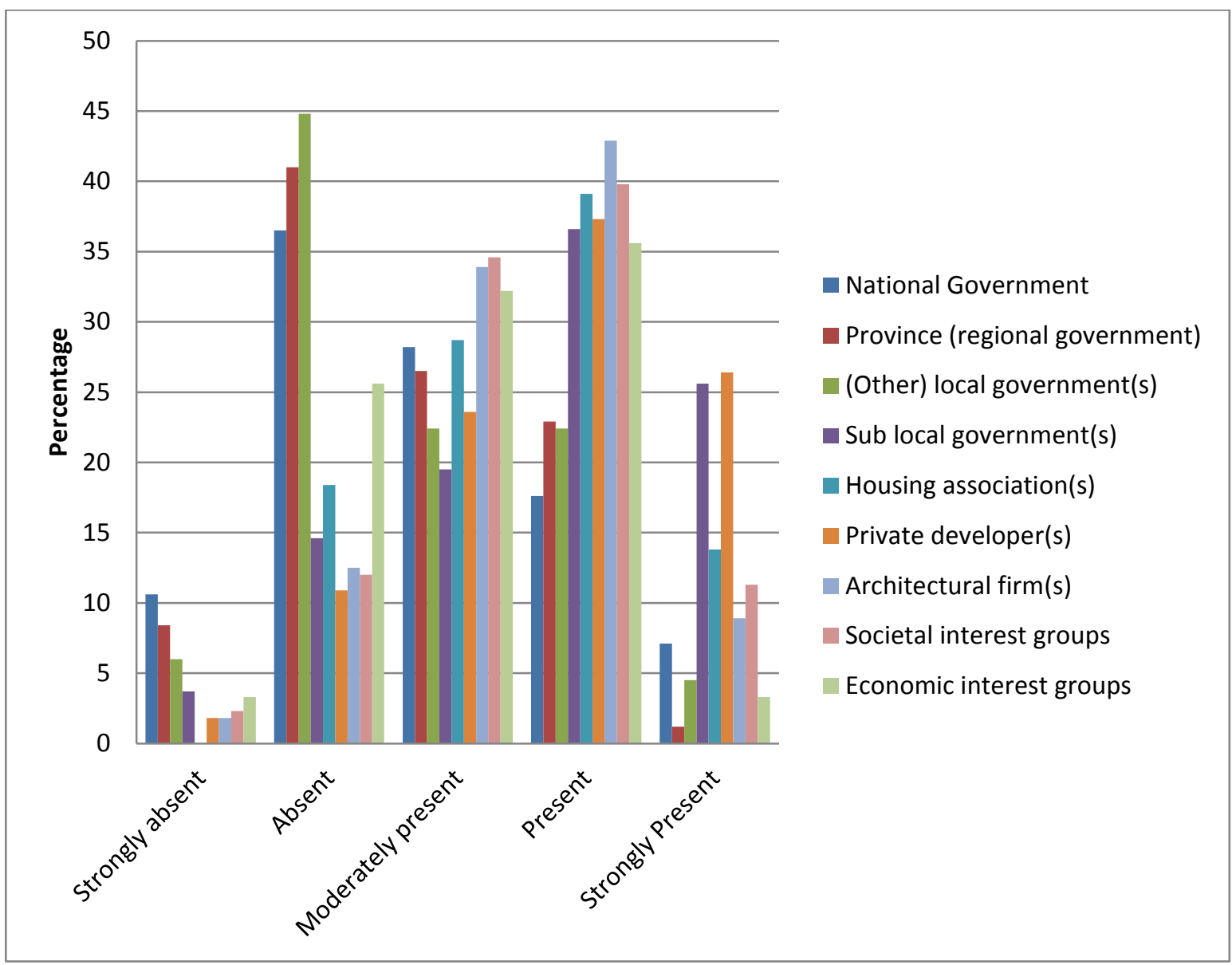


Table 4 Descriptive Statistics and Correlations between Variables in Analysis

\begin{tabular}{|l|r|r|r|r|l|l|l|l|l|}
\hline & Mean & \multicolumn{1}{l}{$\begin{array}{l}\text { St. } \\
\text { D. }\end{array}$} & BS & Trust & NP & TC & PP & YE & YI \\
\hline $\begin{array}{l}\text { Boundary spanners (1- } \\
\text { 5) }\end{array}$ & 3.37 & .67 & 1 & & & & & & \\
\hline Trust (1-5) & 3.34 & .64 & $.551^{* *}$ & 1 & & & & & \\
\hline $\begin{array}{l}\text { Network performance } \\
\text { (1-5) }\end{array}$ & 3.73 & .58 & $.440^{* *}$ & $.402^{* *}$ & 1 & & & & \\
\hline Task complexity (1-6) & 3.16 & .83 & $.194^{*}$ & $.211^{*}$ & .114 & 1 & & & \\
\hline Project phase (1-6) & 3.21 & 1.34 & $.211^{*}$ & $.223^{* *}$ & .164 & .131 & & & \\
\hline Years of experience & 13.01 & 7.23 & -.003 & .096 & .026 & .052 & .035 & & 1 \\
\hline Years of involvement & 2.99 & 2.12 & .129 & .091 & .077 & .131 & $.280^{* *}$ & $.191^{*}$ & 1 \\
\hline
\end{tabular}

$* * \mathrm{p}<0.01 ; * \mathrm{p}<0.05$

$\mathrm{N}$ is in between 133-141 (pairwise deletion of missing values) 
Figure 3 Boundary Spanners, Trust, and Network Performance ${ }^{a}$

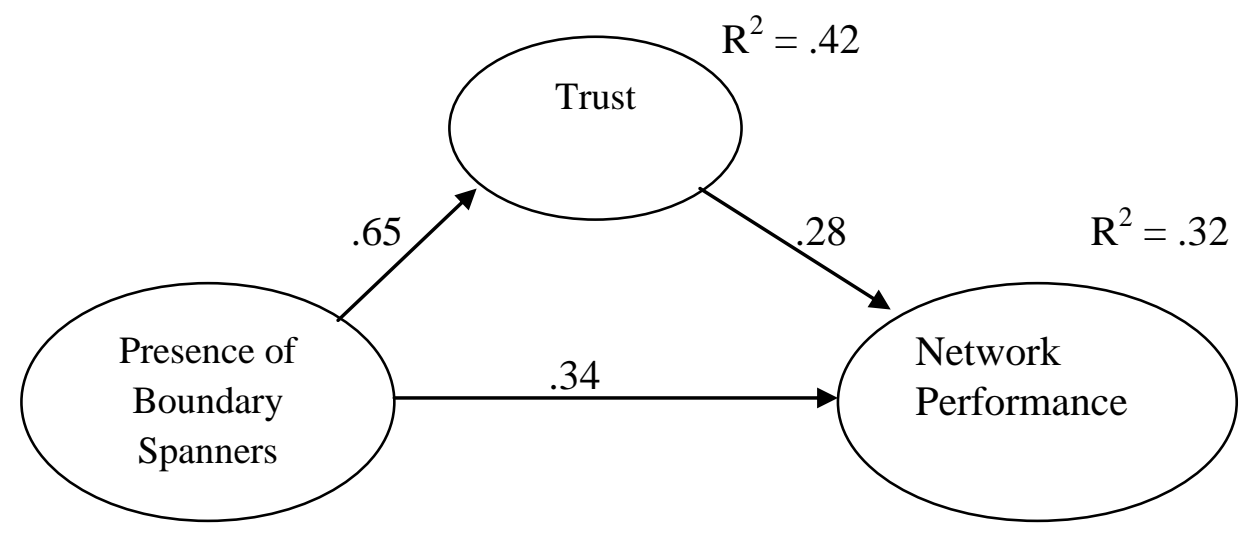

a. Goodness-of-fit statistics: Comparative Fit Index $(\mathrm{CFI})=.97 ; \chi 2 / d f=1.22$. Badness-of-fit statistics: Rood Mean Square Error (RMSEA): 0.04; closeness of fit RMSEA (PCLOSE): .73 